\title{
THERMAL CONDUCTIVITY OF ETHYLENE VINYL ACETATE COPOLYMER/NANOFILLER BLENDS
}

\author{
S. Ghose ${ }^{1}$, K.A. Watson ${ }^{1}$, D.C. Working ${ }^{2}$, J.W. Connell ${ }^{2}$, J.G. Smith, Jr. ${ }^{2}$, Y. Lin ${ }^{3}$ and Y.P. Sun ${ }^{4}$ \\ ${ }^{1}$ National Institute of Aerospace, Hampton, VA 23666-6147 \\ ${ }^{2}$ NASA Langley Research Center, Hampton, VA 23681-2199 \\ ${ }^{3}$ NASA Postdoctoral Fellow at NASA LaRC, Hampton, VA 23681-2199 \\ ${ }^{4}$ Dept of Chemistry, Clemson University, Clemson, SC 26934-0973
}

\begin{abstract}
To reduce weight and increase the mobility, comfort, and performance of future spacesuits, flexible, thermally conductive fabrics and plastic tubes are needed for the Liquid Cooling and Ventilation Garment. Such improvements would allow astronauts to operate more efficiently and safely for extended extravehicular activities. As an approach to raise the thermal conductivity (TC) of an ethylene vinyl acetate copolymer (Elvax ${ }^{\mathrm{TM}} 260$ ), it was compounded with three types of carbon based nanofillers: multi-walled carbon nanotubes (MWCNTs), vapor grown carbon nanofibers (CNFs), and expanded graphite (EG). In addition, other nanofillers including metallized CNFs, nickel nanostrands, boron nitride, and powdered aluminum were also compounded with Elvax ${ }^{\mathrm{TM}} 260$ in the melt at various loading levels. In an attempt to improve compatibility between Elvax ${ }^{\mathrm{TM}} 260$ and the nanofillers, MWCNTs and EG were modified by surface coating and through noncovalent and covalent attachment of organic molecules containing alkyl groups. Ribbons of the nanocomposites were extruded to form samples in
\end{abstract}


which the nanofillers were aligned in the direction of flow. Samples were also fabricated by compression molding to yield nanocomposites in which the nanofillers were randomly oriented. Mechanical properties of the aligned samples were determined by tensile testing while the degree of dispersion and alignment of nanoparticles were investigated using high-resolution scanning electron microscopy. TC measurements were performed using a laser flash (Nanoflash ${ }^{\mathrm{TM}}$ ) technique. TC of the samples was measured in the direction of, and perpendicular to, the alignment direction. Additionally, tubing was also extruded from select nanocomposite compositions and the TC and mechanical flexibility measured.

Keywords: Elvax ${ }^{\mathrm{TM}}$, thermal properties (B), extrusion (E), nanostructures (A), polymer matrix composites (A)

This paper is work of the U. S. Government and is not subject to copyright protection in the U.S.

Corresponding author: Sayata Ghose, fn.s.ghose@larc.nasa.gov, 1-757-864-2094 


\section{INTRODUCTION}

The development of lightweight, high thermal conductivity (TC), flexible materials for potential use in the Liquid Cooling and Ventilation Garment (LCVG) is of interest to NASA. The LCVG is an integral component of the spacesuit that serves to remove body heat from astronauts. By improving the TC of the LCVG subcomponents (i.e., flexible fabric and cooling tubes), a reduction in the total weight of the cooling tubes can be realized, resulting in improved mobility and comfort. These improvements may lead to new, more advanced spacesuit designs that enable longer extravehicular excursions by future astronauts. One approach to enhancing the TC of the polymeric components has been to add nanoparticles which possess high TC. Various nanofillers used in this work are briefly described in the subsequent paragraphs.

Carbon based nanoparticles are one type of material that is commonly used to improve the physical, electrical, and thermal properties of polymers and include expanded graphite (EG), carbon nanofibers (CNFs), and carbon nanotubes (CNTs). CNFs are highly graphitic fibers produced by a catalytic vapor deposition process and have been widely used as reinforcements for polymers like polyethylene [1], polypropylene [2,3], polycarbonate [4], nylon [5], and poly(methyl methacrylate) [6] in numerous high-technology applications. CNTs have high mechanical and electrical properties and ultra high TC $[7,8]$ and CNT-based composites are

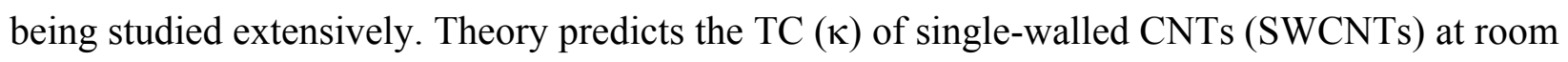
temperature to be as high as $\sim 6600 \mathrm{~W} / \mathrm{mK}$ [9] while the experimental value for an individual MWCNT has been reported as $3000 \mathrm{~W} / \mathrm{mK}$ at room temperature [10]. This value is significantly higher than that of known thermally conducting materials like diamond (up to $2300 \mathrm{~W} / \mathrm{mK}$ ) and graphite (up to $1960 \mathrm{~W} / \mathrm{mK}$ ). EG has excellent thermal and electrical properties, is one of the 
stiffest materials found in nature and presently costs two orders of magnitude less than CNTs [11]. With appropriate surface treatment, dispersion of EG in a polymer matrix results in composites with excellent mechanical and electrical properties and high TC [12 - 17].

Recent research has demonstrated the ability to functionalize nanomaterials such as layered silicate nanoclays, CNTs and CNFs, EG, and silica nanoparticles with a layer of highly conductive metal such as copper $(\mathrm{Cu})$, silver $(\mathrm{Ag})$, or nickel (Ni) [18]. Polymer nanocomposites (PNCs) of Ag-metallized CNFs have very high electrical conductivity and exhibit excellent shielding effectiveness [19]. Based on the results of previous studies, it was anticipated that these materials would also enhance the TC of Elvax based nanocomposite.

Neat metallic materials have also been reported to increase the TC of composites and include $\mathrm{Ni}$ nanostrands and aluminum (Al) particles. Ni nanostrands are receiving increasing attention as an electrically conductive additive in polymers and composites. They are grown as an interconnected three-dimensional lattice of sub-micron and nanostructured strands of nickel and are paramagnetic in nature $[20,21]$. Al-containing particles have also been used to enhance the TC of polymers [22]. Thus it was of interest to investigate the use of a combination of Al particles and some of the above mentioned nanofillers as an approach to achieving greater improvements in TC.

Inorganic compounds such as boron nitride $(\mathrm{BN})$ have been used to improve the $\mathrm{TC}$ of some ceramics with the resultant composites showing a considerable degree of anisotropy in TC [23]. BN powders are highly pure single crystal hexagonal platelets with particle sizes between 6 and 
$13 \mu \mathrm{m}$. The TC is also expected to be high for BN nanotubes whose parent material h-BN has exceptional ab-plane TC [24].

The main problem with the use of these nanofillers is the difficulty in dispersing them in a polymer matrix. For example, to solve the dispersion problem usually associated with CNTs, various methods have been attempted which include preparation of the polymer in the presence of CNTs under sonication [25], the use of alkoxysilane terminated amide acid oligomers [26], melt mixing [27], high shear mixing [28], the use of surfactants and covalent functionalization of the CNTs with various groups. Covalent functionalization has been primarily achieved through carboxylic acid moieties generated on the CNT surface after oxidative treatment [29].

The prominent thermal properties of CNTs have made them one of the most promising materials for future applications as thermal management materials and hence their preferred choice in this work. Enhancement of TC has been observed in CNT suspensions [30-31] with the measured $\mathrm{TC}$ values generally greater than theoretical predictions made with conventional heat conduction models. In the case of SWCNTs, peak TC falls off at higher temperatures due to Umklapp scattering [32]. For carbon-carbon composites, there is a larger mean free path and less phononphonon Umklapp scattering causing the TC to increase linearly with heat treatment temperature [33]. Research in our lab has shown improvements in TC upon addition of MWCNTs and CNFs to a polyimide $[34,35]$. However in PNCs, the improvement in TC has always been lower than rule-of-mixture values. In addition to the dispersability issue, another reason that anticipated TC enhancements are not realized is that of thermal interface resistance or Kapitza resistance [36]. This resistance represents a heat flow barrier associated with the differences in the phonon 
spectra of the two phases and weak contact at the interface, both of which lead to phonon backscattering. One approach of reducing this interface problem is by covalent attachment of CNTs to the matrix. Molecular dynamics simulation on SWCNTs showed that functionalization with octane on one out of $15 \mathrm{CNT}$ carbon atoms ( $7 \%$ functionalization) reduced the thermal interface resistance more than three times. However, it was also reported that these attachments can act as phonon scattering centers themselves and thus reduce CNT conductivity [37]. The effect of functionalization of SWCNTs on the TC of nanocomposites has also been studied using a multi-scale modeling approach. These results predict that grafting linear hydrocarbon chains to the surface of a SWCNT with covalent chemical bonds should result in a significant increase in the TC of these nanocomposites [38].

The primary objective of this work was to enhance the TC of Elvax ${ }^{\mathrm{TM}} 260$ by nanofiller addition. This polymer is currently used in tubing application since it provides outstanding toughness and resilience while maintaining flexibility over a broad temperature range without the need for plasticizers. Melt compounding was chosen as the method to disperse nanoparticles in Elvax ${ }^{\mathrm{TM}}$ 260 because the technique involves shear mixing, which helps disentangle the nanoparticles and disperse them more uniformly within the matrix. Melt mixing was followed by extrusion in some of the samples described herein. The process of extruding nanocomposite through a suitable die and subsequent drawing led to continuous ribbons of nanocomposites with substantial nanoparticle orientation in the flow direction. Dispersability of the nanoparticles was assessed by high resolution scanning electron microscope (HRSEM) and fabricated specimens were characterized for their room temperature tensile properties and TC. The preparation and 
characterization of samples containing various wt $\%$ loadings of the aforementioned nanoparticles are discussed.

\section{EXPERIMENTAL}

2.1 Materials Elvax ${ }^{\mathrm{TM}}$ 260, a melt processable ethylene vinyl acetate copolymer resin was used as received from E.I. du Pont de Nemours and Co. MWCNTs, VGE-S12 and VGE-S16, were procured from the University of Kentucky. CNF, Pyrograph - III - PR-24 HHT was obtained from Applied Sciences, Inc. and EG (Grade 3775) was received from Asbury Carbons. The graphite already had the galleries expanded by first treating with sulfuric acid and then rapidly heating the sample to $900{ }^{\circ} \mathrm{C}$. The expansion of the graphite was expected to facilitate exfoliation during melt mixing. Metallized $\mathrm{CNFs}(\mathrm{Ag}, \mathrm{Cu}$, and $\mathrm{Ni}$ coated) were obtained from Materials Research Institute, LLC. Ni nanostrands were obtained from Metal Matrix Composites and BN powder (PolarTherm BN, grade PT140) from GE Advanced Ceramics. Al powder was obtained from Alcon-Toyo Industries, Inc. All other chemicals were obtained from commercial sources and used as received.

2.2 Characterization HRSEM images were obtained using a Hitachi S-5200 field emission scanning electron microscope (FE-SEM) equipped with a "through-the-lens" secondary electron detector. Room temperature thin-film tensile properties were determined according to a modified version of ASTM D882 using either four or five specimens $(0.51 \mathrm{~cm}$ wide) per test condition using an Eaton Model 3397-139 $11.4 \mathrm{~kg}$ load cell on a Sintech 2 test frame. The test specimen gauge length was $5.1 \mathrm{~cm}$ and the crosshead speed was $0.51 \mathrm{~cm} /$ minute for the MWCNT, CNF and EG samples. For other samples, the crosshead speed was increased to $50 \mathrm{~cm} / \mathrm{min}$ due to high elongation to break. Thermogravimetric analysis (TGA) was performed on the modified 
MWCNT and EG powder samples using an Auto TGA 2950HR (TA Instruments, DE) in argon at a flow rate of $50 \mathrm{~mL} / \mathrm{min}$. The samples were heated at $20{ }^{\circ} \mathrm{C} / \mathrm{min}$ to $100{ }^{\circ} \mathrm{C}$, held for $0.5 \mathrm{~h}$ to drive off any moisture, and then heated to $600{ }^{\circ} \mathrm{C}$ at a rate of $2.5^{\circ} \mathrm{C} / \mathrm{min}$. The TGA data taken at $500{ }^{\circ} \mathrm{C}$ was used to determine the amount of aliphatic groups present. At this temperature the organic (aliphatic) groups would decompose without affecting the nanofillers. Thermal diffusivity of the molded samples as well as ribbons was measured at $25^{\circ} \mathrm{C}$ using a Netzsch LFA 447 NanoFlash according to ASTM E1461. Sample sizes of $1 \mathrm{~cm}$ x $1 \mathrm{~cm}$ were cut by an Isomet low speed saw with a diamond wafering blade; $12.7 \mathrm{~cm}$ diameter and $0.5 \mathrm{~mm}$ thick with $30 \mathrm{HC}$ diamond (Buehler Ltd). Sample density was calculated by measuring sample dimensions and mass. Specific heat of each test sample was measured by comparing the temperature rise of the sample to the temperature rise of a standard reference sample (Pyrex, TC $\sim 1.09 \mathrm{~W} / \mathrm{mK}, \mathrm{Cp} \sim$ $0.76 \mathrm{~J} / \mathrm{gk}$ ) tested under the same conditions. The steady-state TC was calculated through the equation

$$
\lambda=C_{p} D \rho
$$

where $\lambda$ is $\mathrm{TC}, \mathrm{C}_{\mathrm{p}}$ is specific heat, $\mathrm{D}$ is thermal diffusivity, and $\rho$ is the material density. Samples were sprayed with a thin layer of graphite for uniform thermal adsorption, which was easily rinsed away by solvent (e.g. methanol).

\subsubsection{Coating of 1-dodecylbromide on carbon allotropes (MWCNTs and EG 3775)}

To a three-necked round-bottom flask equipped with a nitrogen inlet, mechanical stirrer, and drying tube was charged EG 3775 (20.0 g). The flask was then flame dried under nitrogen and cooled to ambient temperature. Tetrahydrofuran (THF, $400 \mathrm{~mL}$ ) was added and the mixture sonicated at room temperature for $1 \mathrm{~h}$ in an Ultrasonik $57 \mathrm{X}$ bath operating at $\sim 50 \%$ power and 
degas levels. 1-Dodecylbromide (91.82 g) was subsequently added and rinsed in with $50 \mathrm{~mL}$ THF and the mixture stirred under nitrogen at room temperature for $48 \mathrm{~h}$. The product was recovered by vacuum filtration, washed twice with diethyl ether, and air dried at $110{ }^{\circ} \mathrm{C}$ overnight to afford $19.7 \mathrm{~g}$ of product. The amount of 1-dodecylbromide on the EG was $0.1 \mathrm{wt} \%$ as determined by the weight loss at $500{ }^{\circ} \mathrm{C}$ by TGA. A similar process was carried out using MWCNTs.

\subsubsection{Covalent attachment of 1-dodecylamine on carbon allotropes (EG 3775)}

To a single necked round-bottom flask equipped with a magnetic stir bar and condenser was charged EG 3775 (21.8 g), thionyl chloride (300 g), and N,N-dimethylformamide (2 mL). The mixture was refluxed for $48 \mathrm{~h}$ and excess thionyl chloride removed by distillation. The product was washed with diethyl ether, recovered by vacuum filtration, and dried at $35^{\circ} \mathrm{C}$ for $1 \mathrm{~h}$ under vacuum. The as-isolated material $(22.31 \mathrm{~g})$ was added to a three-necked $500 \mathrm{~mL}$ round-bottom flask equipped with a nitrogen inlet, mechanical stirrer, and drying tube. $N, N$-Dimethylacetamide $(200 \mathrm{~mL})$ and 1-dodecylamine $(12.8 \mathrm{~g})$ were then added and the mixture stirred at room temperature under nitrogen for $48 \mathrm{~h}$. The product was recovered by vacuum filtration, washed with ethanol, and air dried at $50{ }^{\circ} \mathrm{C}$ overnight in flowing air to afford $22.54 \mathrm{~g}$ of product. The amount of 1-dodecylamine was $4.1 \mathrm{wt} \%$ as determined by the weight loss at $500{ }^{\circ} \mathrm{C}$ by TGA.

2.4.1 Melt mixing of Elvax ${ }^{\mathrm{TM}} 260$ with nanofillers Elvax ${ }^{\mathrm{TM}} 260$ was compounded with MWCNTs, CNFs and EGs in a $60 \mathrm{cc}$ internal mixer (Plasticorder PL2000, Brabender) for $3 \mathrm{~h}$ at $25 \mathrm{rpm}$ and $125{ }^{\circ} \mathrm{C}$ under a $\mathrm{N}_{2}$ purge. MWCNTs (20 and $30 \mathrm{wt} \%$ ), CNFs (20, 30 and $40 \mathrm{wt} \%$ ), and $\mathrm{EG}(20,30$, and $40 \mathrm{wt} \%)$ were added to the polymer. $30 \mathrm{wt} \% \mathrm{Al}$ powder was melt mixed 
with 20 and $30 \mathrm{wt} \%$ loadings of MWCNTs, CNFs and EG. Attempts at mixing the polymer with higher nanofiller loadings ( $40 \mathrm{wt} \%$ ) were not possible as there was not enough polymer to bind the high loading of nanofillers and Al powder. The loading level used for BN was $20 \mathrm{wt} \%$ and 20 and 30 wt \% loading levels of $\mathrm{Ag}, \mathrm{Cu}$ and $\mathrm{Ni}$ coated CNFs and Ni nanostrands were used. During mixing the torque produced was measured and used to calculate the viscosity of the sample. Upon completion of mixing, the material was ground in a Mini-Granulator (Kayeness, Inc.) using a $5.5 \mathrm{~mm}$ screen.

2.4.2 Extrusion of Elvax ${ }^{\mathrm{TM}} \mathbf{2 6 0}$ with nanofillers Samples were extruded through a Laboratory Mixing Extruder (LME, Dynisco, Inc.) with a $0.38 \mathrm{~mm}$ x $19.1 \mathrm{~mm}$ die at a mandrel temperature of $50{ }^{\circ} \mathrm{C}$ and a die temperature of $125{ }^{\circ} \mathrm{C}$. Samples were extruded in the form of continuous ribbons that were 0.1-0.5 mm thick, $10-15 \mathrm{~mm}$ wide, and several meters in length. Tubing was extruded using the same extruder and a $0.476 \mathrm{~cm}$ outer die (o.d.) die head and a $0.3175 \mathrm{~cm}$ mandrel tip at a mandrel temperature of $50{ }^{\circ} \mathrm{C}$ and a die temperature of $130{ }^{\circ} \mathrm{C}$. For Alcontaining samples, ribbons were extruded using a $1.27 \mathrm{~cm}$ single screw extruder (L:D - 15:1) at $10 \mathrm{rpm}$. The CW Brabender extruder was attached to the PL2000 and the temperature at the three zones were $50{ }^{\circ} \mathrm{C}$ (hopper), $115^{\circ} \mathrm{C}$ (barrel mid-section) and $115{ }^{\circ} \mathrm{C}$ (die). Tubing was extruded using a the same extruder with a $0.476 \mathrm{~cm}$ o.d. die head and $0.3175 \mathrm{~cm}$ mandrel tip at $10 \mathrm{rpm}$ and the temperature at the three zones were $50{ }^{\circ} \mathrm{C}$ (hopper), $100{ }^{\circ} \mathrm{C}$ (barrel mid-section) and 105 ${ }^{\circ} \mathrm{C}$ (die).

2.4.3 TC sample fabrication of Elvax ${ }^{\mathrm{TM}} 260$ with nanofillers Samples with parallel alignment of the nanofillers in the flow direction were obtained from cut ribbons of Section 2.4.2. For 
samples with perpendicular nanofiller alignment the following procedure was performed. The extruded ribbons were cut into pieces approximately $2 \mathrm{~cm}$ x $2 \mathrm{~cm}$, then stacked on one side of a 9 $\mathrm{cm} \times 2 \mathrm{~cm} \times 3 \mathrm{~cm}$ (inner diameter i.d.) mold and the remainder of the mold was filled with Elvax $^{\mathrm{TM}} 260$ pellets. The stacked ribbons were compression molded at $80{ }^{\circ} \mathrm{C}$ and $1.72 \mathrm{MPa}$ for 2 h. The molded samples were sliced using the Isomet low speed saw described previously. Randomly oriented samples were made using a Laboratory Mixing Molder (LMM Dynisco, Inc.) and a rectangular mold $(1.52 \mathrm{~mm} \times 38.1 \mathrm{~mm} \times 1.27 \mathrm{~mm})$. A rough blend of materials was added to the mixing bowl of the LMM kept at $125{ }^{\circ} \mathrm{C}$ and maintained for $0.5 \mathrm{~h}$. The blend was dynamically pressed at a rotational speed of $100 \%$ of ram-motor capacity and static pressed to degas, before passing through the nozzle orifice $(\sim 1.6 \mathrm{~mm})$ into the rectangular mold kept at 125 ${ }^{\circ} \mathrm{C}$. The material was then manually compressed at $\sim 4.5 \mathrm{kN}$ and set under pressure from the ram while being air cooled.

For Al-containing samples, specimens were prepared from ribbons using compression molding at $80{ }^{\circ} \mathrm{C}$ and a pressure of $1.72 \mathrm{MPa}$ for $2 \mathrm{~h}$. Samples for TC analysis were prepared from the plaques by cutting them with a diamond wafering blade as above.

\section{RESULTS AND DISCUSSION}

3.1 Modification of MWCNTs and EG 3775 The surface of the MWCNTs and EG 3775 were modified with aliphatic groups through surface coating (electrostatic) and covalent attachment. Electrostatic attachment was accomplished with 1-dodecylbromide and generally resulted in less than 0.2 wt \% loading. An approximate order of magnitude increase in loading was observed with the covalent attachment of 1-dodecylamine through formation of an amide linkage by the 
reaction of the acid chloride modified carbon allotrope and the aliphatic amine. Representative TGA curves of the various modifications to EG 3775 are shown in Figure 1. The TGA data was used to qualitatively determine the wt\% loading of aliphatic groups on the EG. As evident from the figure, there is a higher amount of the aliphatic present via covalent attachment on the EG as there is a greater $w t^{\%} \%$ loss in the TGA curve.

3.2 Processing of Elvax ${ }^{\mathrm{TM}}$ 260/nanofillers Torque values were obtained during mixing in the Plasticorder and used to calculate sample melt viscosities. Table 1 denotes the calculated melt viscosities of the various samples at $125^{\circ} \mathrm{C}$ and a shear rate of $92.5 \mathrm{sec}^{-1}$. The main purpose for obtaining the viscosity data was to evaluate if the nanocomposite samples could be extruded into ribbons using the LME and hence the data is for qualitative evaluation only. It was observed in previous studies [39] that most materials could not be extruded at high filler loadings when the viscosity was above a certain value, typically $5000-6000 \mathrm{MPa}$. But for Elvax ${ }^{\mathrm{TM}} 260$ nanocomposites with loading levels as high as $50 \mathrm{wt} \%$ the melt viscosity was typically within the range of extrusion. As expected, the neat resin had the lowest viscosity and these values increased with increasing nanofiller loading. However, modification of MWCNTs with long chain aliphatic groups lowered the viscosity compared to unmodified MWCNTs at a similar wt $\%$ loading. The torque data for the modified EG went off the lower end of the scale implying that the material exhibited a very low viscosity. Thus the material could not be compared to the unmodified EG. It was also noted that the addition of some nanofillers, such as Ni nanostrands and BN powder, lowered the melt viscosity and it was assumed that these fillers may have had a plasticizing effect. Figure 2 shows a typical extruded ribbon. The primary purpose of extrusion was to align nanofillers in the flow direction. Stacked ribbons were molded and samples obtained 
by cutting the molded block in the direction of the dotted line in Figure 3 using a diamond saw. In this way samples were obtained with alignment both parallel and perpendicular to the direction of $\mathrm{TC}$ measurement. Figure 4 shows the extruded tubes containing Elvax ${ }^{\mathrm{TM}}$ 260/nanofillers. Some alignment of nanofillers in these tubes was expected although it might not be to the same extent as present in corresponding extruded ribbons.

3.3 HRSEM of nanoparticles and extruded ribbons Figure 5(a) shows the $10 \mathrm{wt} \%$ MWCNT melt mixed ribbon while Figure 5(b) shows the $30 \mathrm{wt} \%$ MWCNT ribbon. In both cases it was observed that MWCNTs were aligned in the flow direction (indicated by the arrow). Figures 5(c) and (d) show the alignment at two CNF loading levels. Here, too, there is significant alignment of nanofibers in the extrusion direction. HRSEM images obtained for the 30 and $40 \mathrm{wt} \%$ EG extruded ribbon [Figure 5 (e \& f)] respectively showed graphite platelets visible at high voltages that varied in size but were all under $1 \mu \mathrm{m}$ in one dimension. By qualitative observation, the particles appeared to be predominantly well dispersed throughout the polymer and this was evident even at low magnifications. Assessment of EG alignment was not easily discernable in these images as well as others not shown due to the shape of the nanoparticle. Figure 6(a) shows the structure of Ni nanostrands while Figure 6(b) shows Ag-CNF samples. As a result of the metal coating on the nanofibers, their diameters have increased thus diminishing the benefit of a large aspect ratio offered by the CNFs. Figure 7(a) shows Al particles in the form of flakes. When compounded with MWCNTs and polymer, most of the flakes were covered by the resin but some uncoated flakes can be discerned [Figure 7(b)]. 
Figure 8(a) shows HRSEM images of the outer surfaces of the Elvax ${ }^{\mathrm{TM}}$ 260/MWCNT extruded tubing. The nanotubes are significantly aligned in the direction of extrusion denoted by the arrow; the effect of which will be discussed later in the paper. Figure 8(b) shows a cross section image of the tubing and MWCNTs can be seen projecting from the polymer matrix.

3.4. Tensile properties of extruded ribbons Tensile properties were measured at room temperature on Elvax ${ }^{\mathrm{TM}}$ 260/nanofiller composites with the results shown in Tables 2a and $2 \mathrm{~b}$. The strips used for testing were cut from extruded ribbons, hence the nanofillers are somewhat aligned in the stress direction. The results should be viewed with care because the measurement of the ribbon thickness was not precise due to the uneven ribbon surfaces. In Table 2a, the testing was done at $0.51 \mathrm{~cm} / \mathrm{min}$, while in Table $2 \mathrm{~b}$ the testing was carried out at $50 \mathrm{~cm} / \mathrm{min}$ in order to reduce the time due to the high elongations. It was seen that the strength of the neat material increased as higher polymer strength is almost always observed for higher strain rates (or shorter testing times) $[40,41]$. The modulus for the neat Elvax ${ }^{\mathrm{TM}} 260$ remained the same. Where the data scatter was low some conclusions were drawn. For a loading level of 20 and $30 \mathrm{wt} \%$, CNF the strengths were comparable and increased with respect to the neat material. At $40 \mathrm{wt} \% \mathrm{CNF}$ and $20 \mathrm{wt} \%$ EG loadings, the strength was lower than that of the neat material. Even with a high data scatter, the metallized CNFs and $30 \mathrm{wt} \% \mathrm{Ni}$ nanostrands exhibited reduced strength compared to the neat Elvax ${ }^{\mathrm{TM}}$ 260. The incorporation of $\mathrm{Al}$ with the carbon based nanofillers resulted in lower strengths and may be due to the very high filler loading. Other discernable strength trends could not can be made due to the large scatter in the data. 
In general, the modulus increased with increasing nanofiller loading as expected. The exception to this was the metallized CNFs and Ni nanostrands which showed either very minor increase (20 wt $\% \mathrm{Ag}-\mathrm{CNF}$ ), no change, or a decrease with respect to the neat material. Modification of EG with alkyl groups afforded a reduction in the modulus compared to neat EG at a similar wt loading. However, the same can not be said for the modified MWCNT and MWCNT at a comparable wt loading due to overlap in the data scatter. For Al containing samples there was a significant increase in modulus compared to Elvax ${ }^{\mathrm{TM}} 260$ due to the high total filler loading. For the carbon nanofillers at a $20 \mathrm{wt} \%$ loading and $30 \mathrm{wt} \% \mathrm{Al}$ loading the modulus decreased in the order of MWCNT $>$ EG $>$ CNF. Additionally modification of the MWCNT resulted in decreasing the modulus compared to the neat MWCNT at 20wt $\%$ loading of the MWCNT type and $30 \mathrm{wt} \% \mathrm{Al}$. The loading (up to $60 \mathrm{wt} \%$ net) caused a significant lowering of elongation and reduced strength of samples.

3.5 Thermal conductivity measurements Since the structure of the nanofillers is anisotropic in space, the electrical and thermal properties should be different in the axial (parallel to nanotube/fiber axis) and transverse (perpendicular to nanotube/fiber axis) directions. There have been a few reports on the use of dispersed CNTs as thermally conducting fillers in polymer composites and certain enhancements in TC were observed [33, 42]. However, the enhanced values were typically below those predicted by the rule of mixtures. One reason for this is the probable existence of interface thermal resistance between the overlaps in the CNT passage leading to a rapid increase in overall thermal resistance [43]. Huang, et al. [42] proposed a composite structure where all the CNTs embedded in the matrix were aligned from one surface to the opposite side with all the CNT surfaces revealed on both surfaces. This structure would 
lead to high TC since the CNTs form ideal thermally conducting pathways. Low thermal interface resistances can also be expected as the protruding tips would ensure better thermal contact. Alignment of nanofillers in the polymer matrix has been reported to enhance TC [33, 44]. Based on the literature survey to date, it was decided to process samples with significant nanofiller alignment and measure TC both in the direction of and perpendicular to alignment (nanotube/fiber axis).

Three types of Elvax ${ }^{\mathrm{TM}}$ 260/nanofiller samples were measured for TC. These were the extruded ribbon, molded samples cut perpendicular to flow direction, and extruded tubes. For the extruded ribbons and tubing, the $\mathrm{TC}$ was measured perpendicular to the direction of nanofiller alignment. The TC of parallel aligned nanofillers was determined from specimens cut from molded ribbons. In the case of samples containing only MWCNTs, CNFs, or EG another set which had random alignment was also examined. Table 3 denotes the values for neat Elvax ${ }^{\mathrm{TM}} 260$ and Elvax ${ }^{\mathrm{TM}}$ 260/nanofiller samples. The TC increased with increasing loading level of nanofillers in many cases and was dependent upon alignment. The first set of samples (Table 3, column 1) was for extruded ribbons where the TC was determined perpendicular to the nanofiller. For BN samples no improvement in TC was observed. For metallized CNF samples and Ni nanostrands, the surface was too rough and measurements were unsuccessful despite several attempts. Only the TC for the $20 \mathrm{wt} \% \mathrm{Ag}-\mathrm{CNF}$ sample could be determined and even though the value was higher than the neat sample, it was lower compared to a similar loading of CNFs. The highest TC was observed in Al samples with a loading of $30 \mathrm{wt} \%$ MWCNT. The TC increased more than 3-fold and similar increases were observed with CNF and EG containing Al samples. In the case of samples without Al, the modified (electrostatic attachment) MWCNT sample had a higher TC 
value compared to the unmodified sample having the same loading level. However, the same trend was not observed in the case of modified (electrostatic attachment) EG samples.

The second set of samples comprised of the molded samples where the TC was measured in the direction of nanofiller alignment (parallel to nanofiller axis) as shown in Table 3 (column 2). The TC of these samples was observed to be significantly greater when compared to those perpendicular to alignment (column 1). It was observed that TC values of metallized CNFs and Ni nanostrands were higher compared to the neat polymer with 50\% improvement for the $\mathrm{Ag}$ CNF samples, $67 \%$ improvement for the $\mathrm{Cu}-\mathrm{CNF}$ samples, and a 2-fold increase for the Ni-CNF samples. For Ni nanostrands the improvement was about 70\%. Comparisons between the two alignment types for these samples could not be assessed due to the reason previously mentioned. However for the $20 \mathrm{wt} \%$ Ag-CNF sample, the parallel alignment exhibited a $41 \%$ improvement in TC compared to the perpendicular TC. For BN and Al-loaded samples, TC was observed to be significantly greater in the direction of alignment compared to perpendicular to alignment. The BN sample showed a 2.5 -fold improvement in TC. MWCNT samples at $30 \mathrm{wt} \%$ loading exhibited a 9.1-fold increase in TC relative to neat Elvax ${ }^{\mathrm{TM}} 260$ whereas CNF samples loaded at $40 \mathrm{wt} \%$ showed a 12.1-fold increase. The largest TC increase, 17.1 -fold, was exhibited by $40 \mathrm{wt}$ $\%$ loading of EG samples. The data suggested that aligned nanofillers form a network to successfully conduct heat by perhaps enabling a more efficient phonon transfer from one filler particle to another. Comparing neat and modified (electrostatic attachment) MWCNTs, it was observed that TC showed a 10.5 -fold improvement upon modification compared to a 7 -fold improvement in the unmodified sample. However, for the modified (electrostatic attachment) EG sample, the improvement in TC was 14 -fold compared to 17 -fold for the unmodified material. 
For Al samples, the MWCNT samples at $30 \mathrm{wt} \%$ loading exhibited a 11.8 -fold increase in TC relative to neat Elvax ${ }^{\mathrm{TM}}$ 260, whereas the CNF samples loaded at $30 \mathrm{wt} \%$ showed an 11.3-fold increase. The $20 \mathrm{wt} \%$ loading of EG samples showed a 10.3-fold improvement and was slightly better than the TC of the $20 \mathrm{wt} \%$ MWCNT sample and significantly greater than the $20 \mathrm{wt} \%$ CNF sample. When compared to samples without Al particles, it was seen that the addition of $\mathrm{Al}$ significantly improved the TC of samples, by as much as $30 \%$, as observed in the case of $30 \mathrm{wt}$ $\%$ MWCNT.

EG is a loose and porous product and its structure is basically parallel sheets, which collapse and deform resulting in many pores of different sizes ranging from $10 \mathrm{~nm}$ to10 $\mu \mathrm{m}$. Because of the high expansion ratio (generally200 -300) of expanded graphite in c-axis, galleries of expanded graphite can be easily intercalated by suitable polymers [45]. Thermal conduction systems containing expanded graphite are "attached" systems in which expanded graphite particles interact with each other and affect the position of expanded graphite particles. Hence, the EG samples exhibit high TC values.

TC was measured for extruded tubes as well. Extrusion of tubes was carried out with the MWCNT, $\mathrm{CNF}$, and EG loaded and $\mathrm{Al} /$ nanofiller samples as these specimens showed promising TC values in the form of ribbons. HRSEM revealed alignment of the nanofillers along the length of the tubes and TC measurements were made in the direction of the tube axis. As seen in Table 3 (column 3) for the Al loaded samples, $30 \mathrm{wt} \%$ loading of MWCNTs improved the TC 18.5fold (compared to 17 -fold in samples without $\mathrm{Al}$ ) while the same loading of CNF improved TC 18.4-fold (compared to 13-fold in samples without Al). For $30 \mathrm{wt} \%$ EG samples, the 
improvement was 24-fold (compared to 15.5-fold in samples without $\mathrm{Al}$ ) and a sharp increase in TC was observed when loading levels increased from 20 to $30 \mathrm{wt} \%$ for Al loaded samples. However, the modified (electrostatic attachment) MWCNT sample did not show an increase compared to the unmodified MWCNTs when the samples were loaded with Al. This is in contrast to the samples without Al where modified (electrostatic attachment) MWCNTs improved the TC compared to unmodified MWCNTs. Also, MWCNTs modified by covalent attachment had a lower TC value compared to that with noncovalent attachment, possibly due to the presence of more phonon scattering centers. In general, the tubes exhibited a slightly higher TC compared to the same composition of molded samples when measured in the direction of alignment.

The highest TC value for the randomly oriented samples (Table 4) was exhibited by $50 \mathrm{wt} \%$ modified (covalent) EG sample that showed a 7.6-fold increase. Again, modified (electrostatic) MWCNT samples showed higher TC values compared to the unmodified ones while the opposite was observed for modified (electrostatic) EG samples. TC results from the LMM samples proved conclusively that alignment of nanofillers in the polymer matrix significantly raised the TC of the samples. However, unaligned samples also showed a significant improvement and may be useful in applications when it is not possible to achieve nanoparticle alignment in a desired direction.

3.6 Radius of curvature of tubing Disadvantages with the current LCVG are that it is heavy and restricts mobility due to the large number of rigid cooling lines. An analytical study performed by Lockheed Martin Space Operations concluded that significant improvements in 
weight, comfort, and mobility of the LCVG could be achieved by increasing the TC of the fabric and the plastic cooling lines [46]. Although the incorporation of various nanofillers has significantly improved the $\mathrm{TC}$, it is also necessary to ensure that the flexibility of the cooling tubes is not compromised so that they can be effectively woven into the fabric. Flexibility of the extruded tubes was tested by using a series of stainless steel cylinders of varying diameter. Each tube was wound around the cylinder of a particular diameter and the smallest diameter that the tube could be wound around without kinking was noted. Table 5 shows the data from these flexibility tests. It was observed that for Al loaded samples (Table 5a) at loading levels of $20 \mathrm{wt}$ \%, CNF, EG, MWCNT and modified MWCNT-filled Elvax ${ }^{\mathrm{TM}} 260$ had high flexibility. At $30 \mathrm{wt}$ \% loading level only the EG samples showed kinking at the smallest diameter. These data exhibit a significant improvement on samples without $\mathrm{Al}$ (Table 5b) where only the $\mathrm{CNF}$ and modified MWCNT samples showed no kinking and the EG samples showed substantial kinking. For samples without $\mathrm{Al}$, it was observed that at loading levels of 20 and $30 \mathrm{wt} \%$, CNF filled Elvax $^{\mathrm{TM}} 260$ had the highest flexibility and the EG filled polymer had least. Typically the EG filled samples had higher TC but as evident from Figure 7, at higher loading levels they had a greater tendency to kink. However, alkyl-modified nanofillers yielded a significant improvement in flexibility as seen in the cases of the $20 \mathrm{wt} \%$ modified (electrostatic) MWCNT and the $40 \mathrm{wt}$ $\%$ modified (electrostatic) EG. When 20 and $30 \mathrm{wt} \%$ modified (covalent) EG samples were tested, they exhibited greater flexibility compared to their unmodified counterparts. In all cases modification (covalent or electrostatic) improved the flexibility but the effect on the TC varied. It was possible that the alkyl groups provided a plasticizing effect. 


\section{SUMMARY}

Elvax $^{\mathrm{TM}} 260$ was mixed with various nanofillers in an effort to increase the TC of the polymer without significantly sacrificing flexibility. After initial mixing, the nanocomposites were extruded or processed via the LMM process. HRSEM revealed significant alignment of the nanofillers in the flow direction in the extruded samples. TC measurements were made both in the direction of and perpendicular to nanofiller alignment, for tubes along their lengths as well as for unaligned samples. For ribbon samples it was found that the largest improvement in TC was achieved in the case of aligned samples when the measurement was performed in the direction of alignment. Unaligned samples also showed an improvement in TC and may be useful in applications when it is not possible to align the nanofiller. For extruded ribbons and molded samples, modification (electrostatic) of MWCNTs led to significant improvement in the TC value compared to the composite containing unmodified MWCNTs but this behavior was not seen for the modified (electrostatic) EG sample. However, for tubes containing modified (covalent or electrostatic) nanofillers, all samples showed improvement in flexibility but the effect on TC varied. It was also observed that the addition of Al particles to the polymer loaded with nanofillers improved the TC significantly without compromising flexibility. When all four types of samples were compared, the extruded tubes showed the highest TC. Improvements in TC did not approach those expected based on a rule of mixtures and this was likely due to poor phonon transfer through the matrix. Finally when the TC, flexibility, and material cost were taken into consideration, it was concluded that compositions with 20 and $30 \mathrm{wt} \%$ loading of CNF and the modified (electrostatic) MWCNT and EG compositions produced composites of high TC and good flexibility. The 20 and $30 \mathrm{wt} \%$ loading levels of EG and $30 \mathrm{wt} \% \mathrm{Al}$ powder exhibited excellent flexibility, high TC, and are cost effective. The use of Al powder and EG to 
improve the TC of the cooling tubes of the LCVG subcomponents appears attractive and additional testing of cooling tubes comprised of these materials is warranted.

\section{ACKNOWLEDGEMENT}

The authors would like to thank Asbury Carbons for providing the EG and Tom Hughes and Applied Sciences, Inc. for providing the CNFs. Many thanks to Dr. Marcus A. Belcher, National Institute of Aerospace, and Dr. Emilie Siochi, NASA LaRC, for their valuable comments and discussions. 


\section{FIGURES AND TABLES}

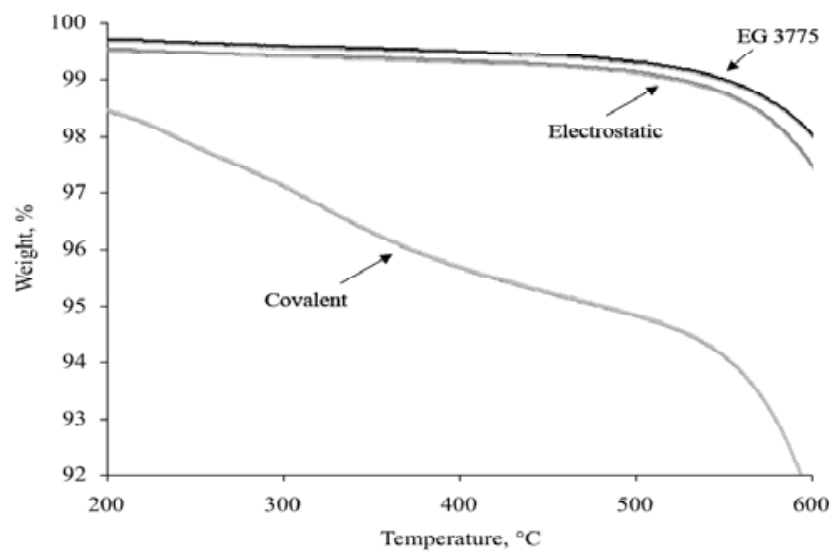

Figure 1: TGA in argon of EG 3775 (pristine), electrostatic (1-dodecylbromide), and covalent (1dodecylamine) modification.

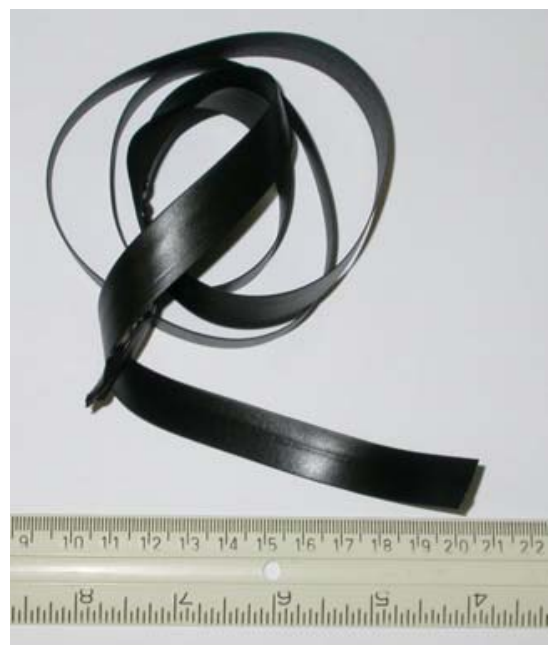

Figure 2: Ribbon of Elvax ${ }^{\mathrm{TM}}$ 260/MWCNTs

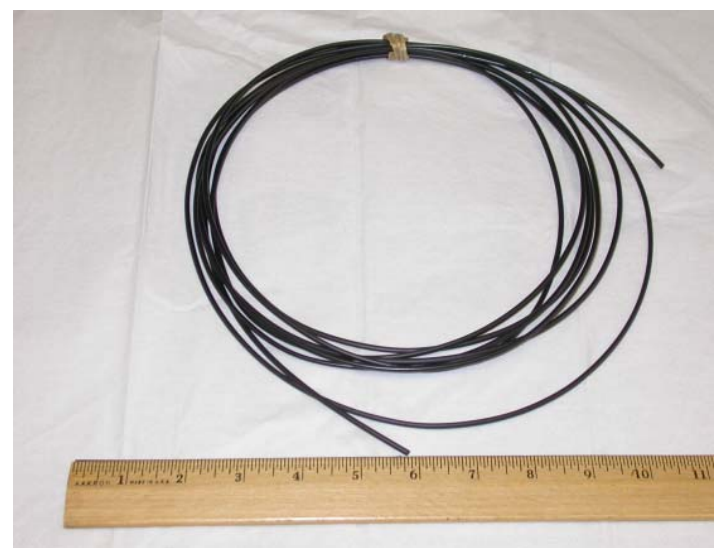

Figure 4: Extruded tubes of Elvax ${ }^{\mathrm{TM}}$ 260/MWCNTs 


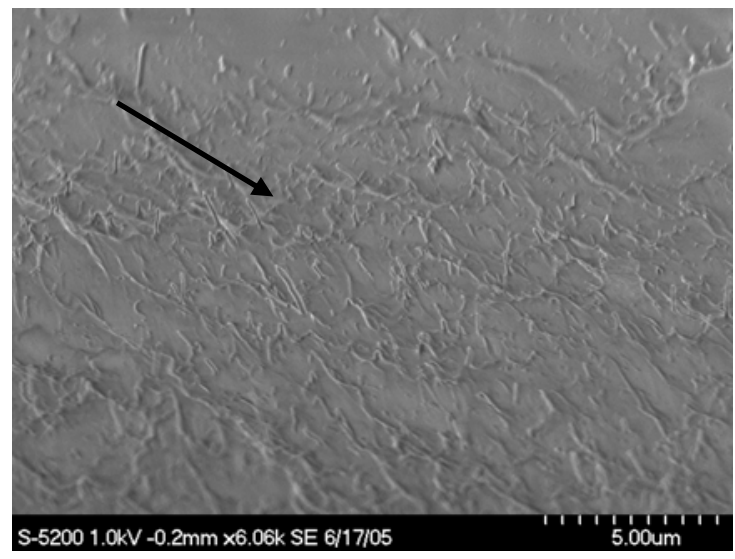

Figure 5(a): $10 \mathrm{wt} \% \mathrm{MWCNT}$

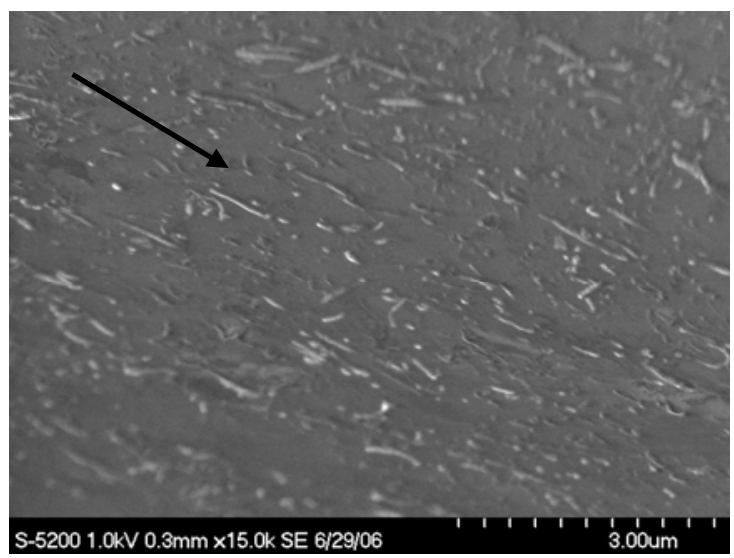

Figure 5(c): $30 \mathrm{wt} \% \mathrm{CNFs}$

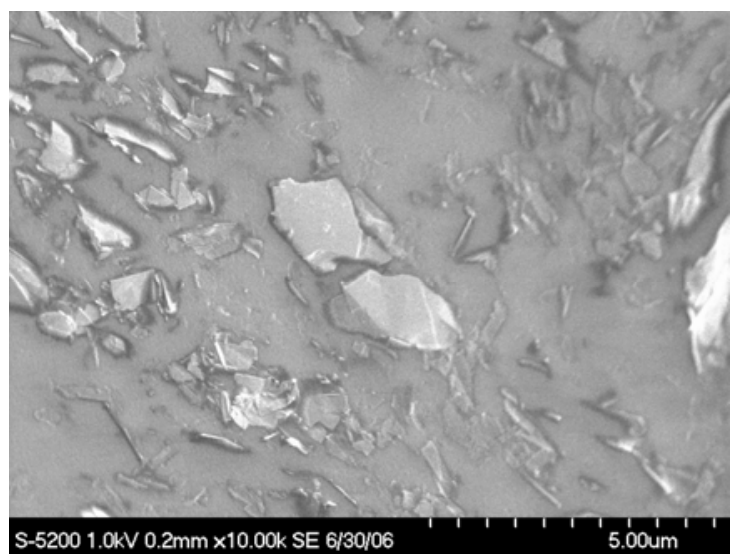

Figure 5(e): $30 \mathrm{wt} \% \mathrm{EG}$

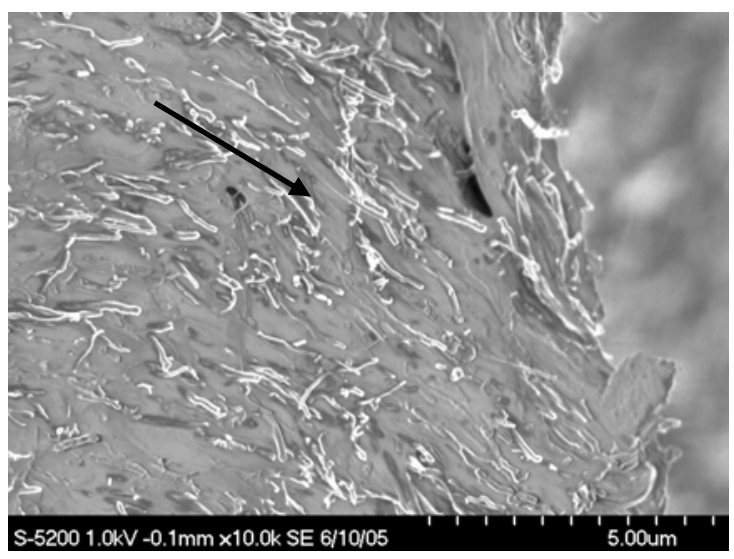

Figure 5(b): $30 \mathrm{wt} \%$ MWCNT

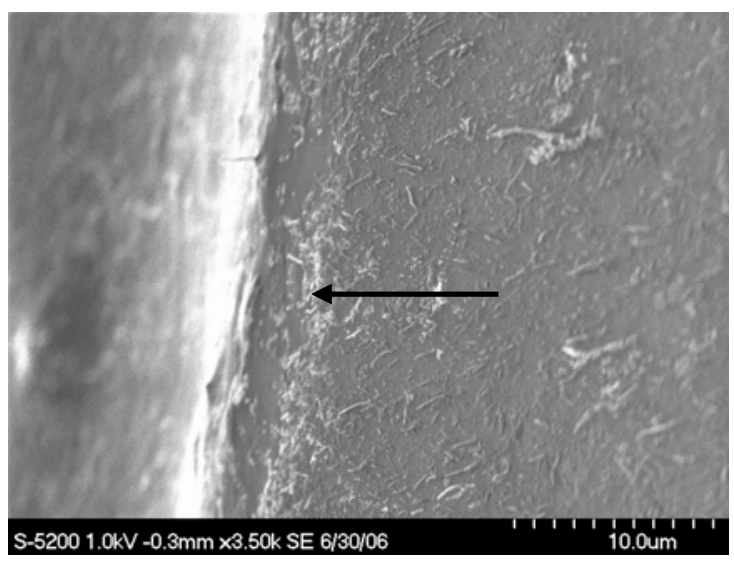

Figure 5(d): $40 \mathrm{wt} \% \mathrm{CNF}$

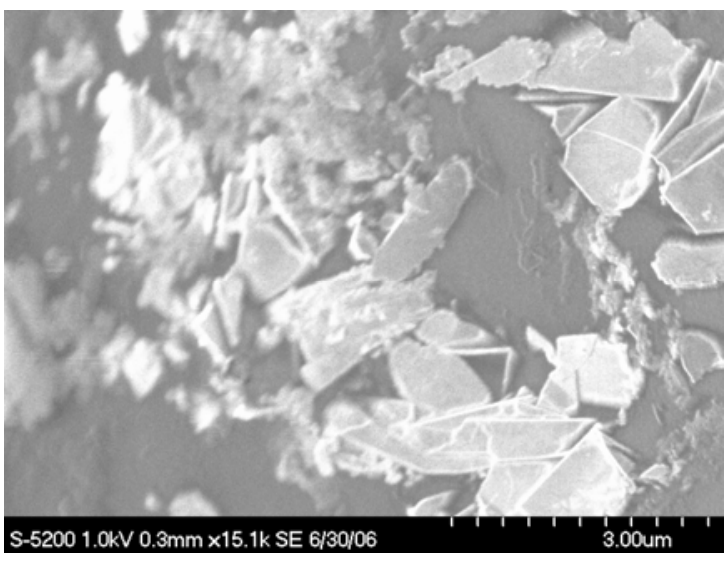

Figure 5(f): $40 \mathrm{wt} \%$ EG

Figure 5: HRSEM of Elvax ${ }^{\mathrm{TM}}$ 260/nanofiller ribbon samples; arrow denotes flow direction 


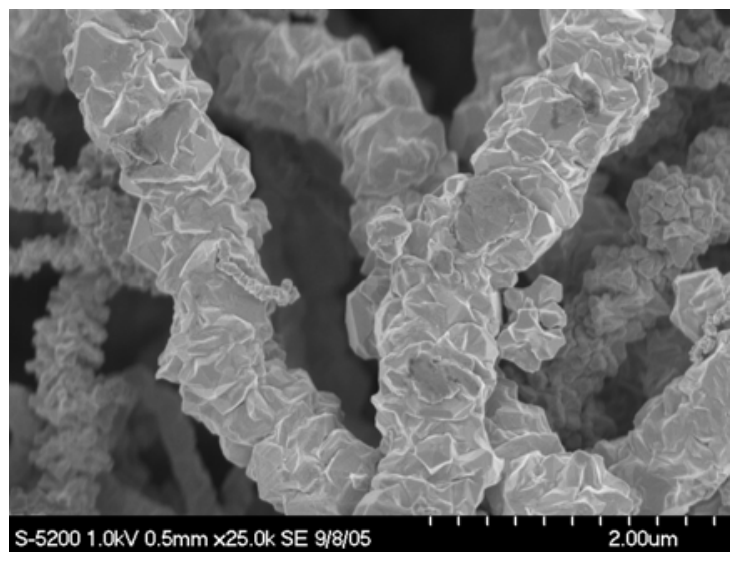

Figure 6(a): Nickel Nanostrands

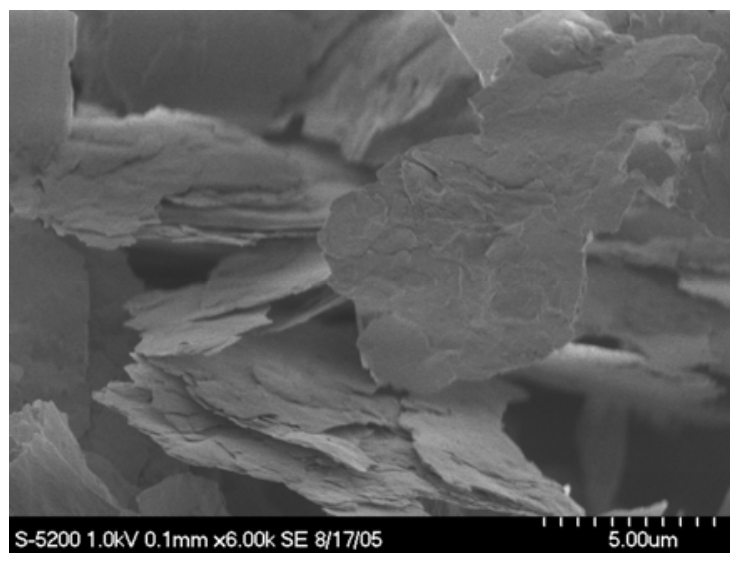

Figure 7(a): Al powder

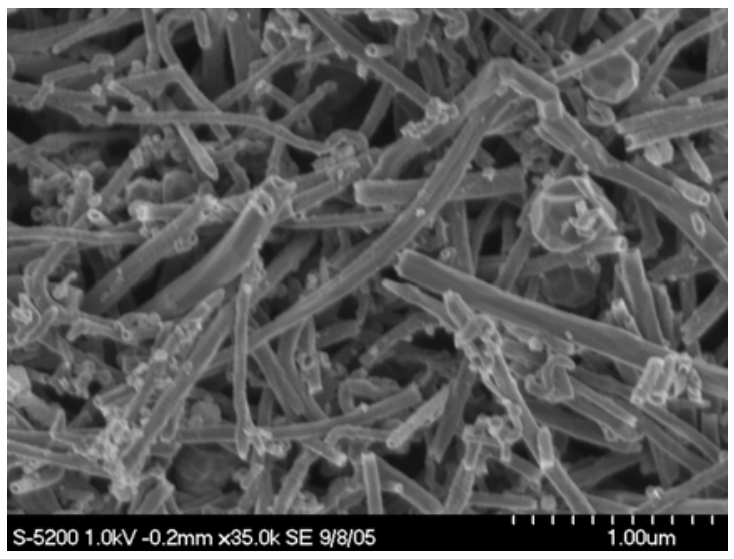

Figure 6(b): Ag-CNF

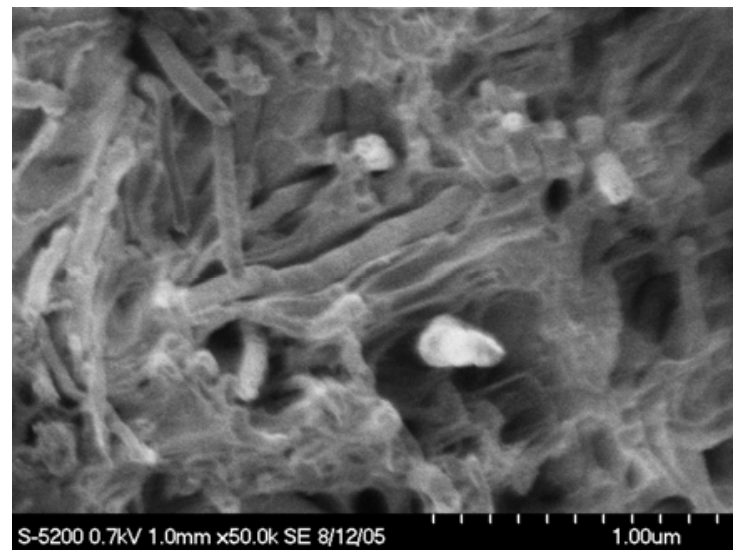

Figure 7(b): Elvax 260 ${ }^{\mathrm{TM}} / \mathrm{Al}$ powder/ MWCNT

Figure 7: Elvax $260^{\mathrm{TM}}$ with Al powder

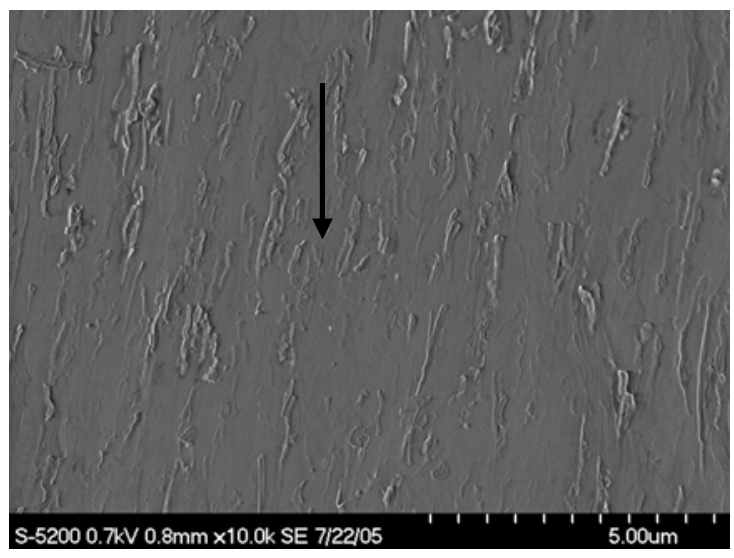

Figure 8(a): $30 \mathrm{wt} \% \mathrm{MWCNT}$

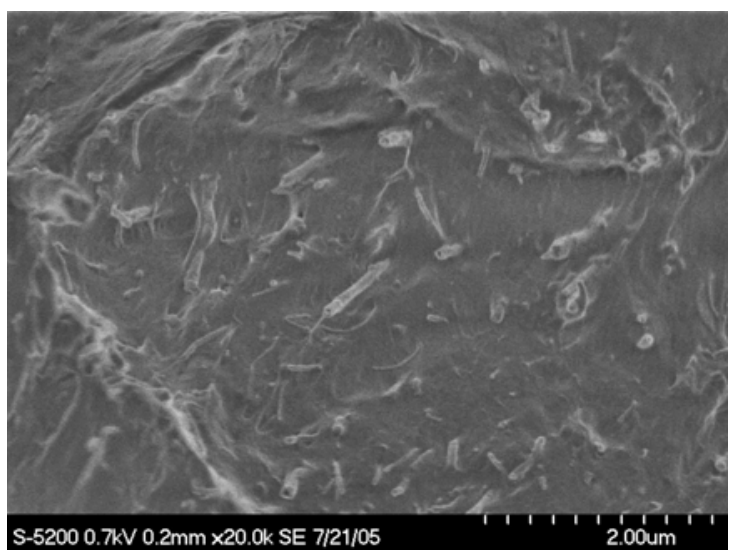

Figure 8(b): $20 \mathrm{wt} \%$ MWCNT

Figure 8: HRSEM of surfaces of Elvax ${ }^{\mathrm{TM}}$ 260/MWCNT tubing 


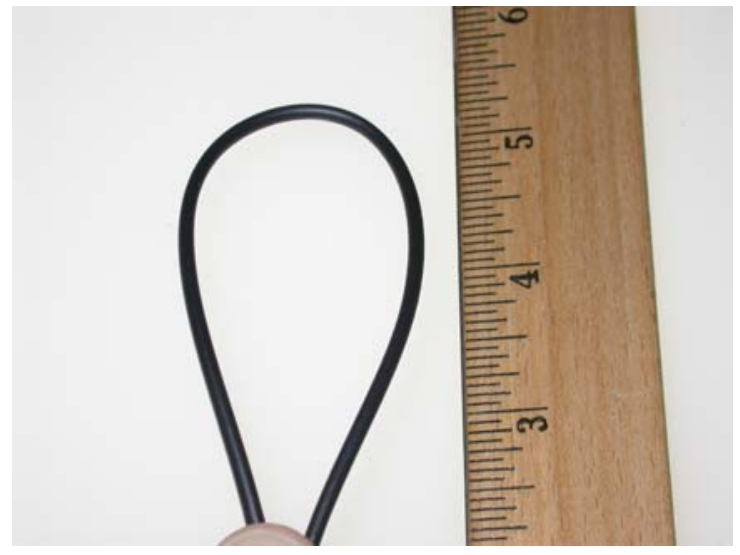

Figure 7(a): No kinks - 30 wt \% MWCNT

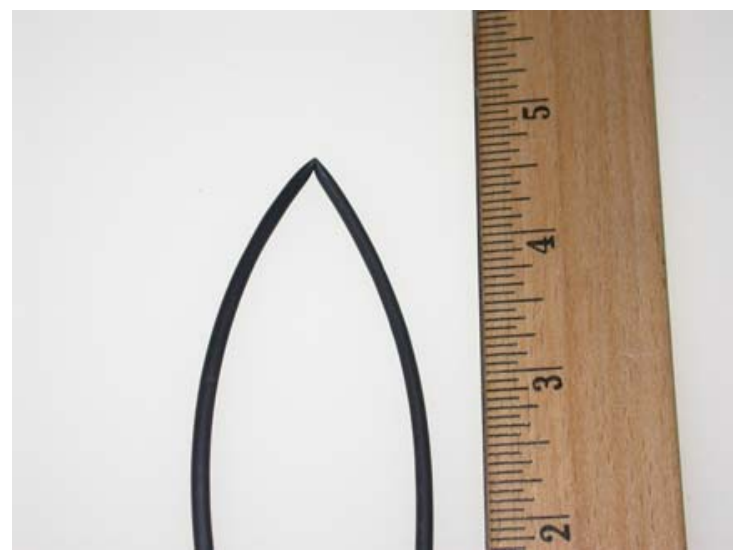

Figure 7(b): Kinking - 30 wt \% EG

Figure 7: Radius of curvature of Elvax ${ }^{\mathrm{TM}}$ 260/nanofiller tubing 
Table 1: Melt viscosities of Elvax ${ }^{\mathrm{TM}}$ 260/nanofiller samples:

\begin{tabular}{|c|c|}
\hline Sample & Viscosity (Pa-s) \\
\hline Neat Elvax TM 260 & 1001 \\
\hline$+20 \mathrm{wt} \% \mathrm{MWCNT}$ & 1878 \\
\hline$+20 \mathrm{wt} \% \bmod$ MWCNT (electrostatic) & 1562 \\
\hline$+30 \mathrm{wt} \% \mathrm{MWCNT}$ & 2269 \\
\hline$+20 \mathrm{wt} \% \mathrm{CNF}$ & 1462 \\
\hline$+30 \mathrm{wt} \% \mathrm{CNF}$ & 1800 \\
\hline$+40 \mathrm{wt} \% \mathrm{CNF}$ & 2299 \\
\hline$+20 \mathrm{wt} \% \mathrm{EG}$ & 1098 \\
\hline$+30 \mathrm{wt} \% \mathrm{EG}$ & 1276 \\
\hline$+40 \mathrm{wt} \% \mathrm{EG}$ & 1347 \\
\hline$+40 \mathrm{wt} \%$ mod EG* (electrostatic) & ------ \\
\hline$+20 \mathrm{wt} \% \mathrm{Ag}-\mathrm{CNF}$ & 940 \\
\hline$+30 \mathrm{wt} \% \mathrm{Ag}-\mathrm{CNF}$ & 1131 \\
\hline$+20 \mathrm{wt} \% \mathrm{Cu}-\mathrm{CNF}$ & 1046 \\
\hline$+30 \mathrm{wt} \% \mathrm{Cu}-\mathrm{CNF}$ & 1067 \\
\hline$+20 \mathrm{wt} \% \mathrm{Ni}-\mathrm{CNF}$ & 1338 \\
\hline$+30 \mathrm{wt} \% \mathrm{Ni}-\mathrm{CNF}$ & 1250 \\
\hline+20 wt $\%$ Ni-nanostrands & 922 \\
\hline$+30 \mathrm{wt} \%$ Ni-nanostrands & 849 \\
\hline$+20 \mathrm{wt} \% \mathrm{BN}$ & 887 \\
\hline$+30 \mathrm{wt} \% \mathrm{Al}+20 \mathrm{wt} \% \mathrm{MWCNT}$ & 1927 \\
\hline$+30 \mathrm{wt} \% \mathrm{Al}+30 \mathrm{wt} \% \mathrm{MWCNT}$ & 2587 \\
\hline $\begin{array}{l}+30 \text { wt } \% \text { Al }+20 \text { wt } \% \text { mod MWCNT } \\
\text { (electrostatic) }\end{array}$ & 1907 \\
\hline$+30 \mathrm{wt} \% \mathrm{Al}+20 \mathrm{wt} \% \mathrm{CNF}$ & 1951 \\
\hline$+30 \mathrm{wt} \% \mathrm{Al}+30 \mathrm{wt} \% \mathrm{CNF}$ & 2564 \\
\hline$+30 \mathrm{wt} \% \mathrm{Al}+20 \mathrm{wt} \% \mathrm{EG}$ & 1418 \\
\hline$+30 \mathrm{wt} \% \mathrm{Al}+30 \mathrm{wt} \% \mathrm{EG}$ & 1604 \\
\hline
\end{tabular}

Shear rate: $92.5 / \mathrm{sec}$, Temperature: $125^{\circ} \mathrm{C}$

* Torque value went off scale 
Table 2a: Mechanical properties of Elvax ${ }^{\mathrm{TM}}$ 260/nanofiller samples $(0.51 \mathrm{~cm} / \mathrm{min})$ :

\begin{tabular}{|l|c|c|c|}
\hline Sample & $\begin{array}{c}\text { Modulus, } \\
\text { GPa }\end{array}$ & $\begin{array}{c}\text { Strength, } \\
\text { MPa }\end{array}$ & $\begin{array}{c}\text { Elongation., } \\
\text { \% }\end{array}$ \\
\hline Neat Elvax ${ }^{\text {TM } 260}$ & $0.01 \pm 0.001$ & $9.7 \pm 0.1$ & $856 \pm 102$ \\
\hline$+20 \mathrm{wt} \%$ MWCNT & $0.07 \pm 0.01$ & $11.1 \pm 2.0$ & $586 \pm 45$ \\
\hline$+20 \mathrm{wt} \%$ mod MWCNT (electrostatic) & $0.06 \pm 0.01$ & $9.0 \pm 1.6$ & $481 \pm 209$ \\
\hline$+30 \mathrm{wt} \%$ MWCNT & $0.12 \pm 0.01$ & $10.2 \pm 4.0$ & $274 \pm 93$ \\
\hline$+20 \mathrm{wt} \%$ CNF & $0.05 \pm 0.01$ & $11.3 \pm 0.3$ & $710 \pm 54$ \\
\hline$+30 \mathrm{wt} \%$ CNF & $0.09 \pm 0.01$ & $11.9 \pm 0.4$ & $537 \pm 4$ \\
\hline$+40 \mathrm{wt} \%$ CNF & $0.13 \pm 0.01$ & $8.1 \pm 0.3$ & $97 \pm 20$ \\
\hline$+20 \mathrm{wt} \%$ EG & $0.06 \pm 0.01$ & $7.7 \pm 1.1$ & $430 \pm 65$ \\
\hline$+30 \mathrm{wt} \%$ EG & $0.10 \pm 0.01$ & $8.9 \pm 0.7$ & $164 \pm 44$ \\
\hline$+40 \mathrm{wt} \%$ EG & $0.18 \pm 0.02$ & $11.9 \pm 2$ & $77 \pm 8$ \\
\hline$+40 \mathrm{wt} \%$ mod EG (electrostatic) & $0.12 \pm 0.01$ & $8.5 \pm 2.4$ & $97 \pm 16$ \\
\hline
\end{tabular}

Table 2b: Mechanical properties of Elvax ${ }^{\mathrm{TM}}$ 260/nanofiller samples (50 cm/min):

\begin{tabular}{|l|c|c|c|}
\hline \multicolumn{1}{|c|}{ Sample } & $\begin{array}{c}\text { Modulus, } \\
\text { GPa }\end{array}$ & $\begin{array}{c}\text { Strength, } \\
\text { MPa }\end{array}$ & $\begin{array}{c}\text { Elongation, } \\
\%\end{array}$ \\
\hline Neat Elvax ${ }^{\mathrm{TM}} 260$ & $0.014 \pm 0.001$ & $17.8 \pm 0.2$ & $900 \pm 15$ \\
\hline$+20 \mathrm{wt} \% \mathrm{Ag}-\mathrm{CNF}$ & $0.017 \pm 0.001$ & $16.0 \pm 0.1$ & $814 \pm 57$ \\
\hline$+30 \mathrm{wt} \% \mathrm{Ag}-\mathrm{CNF}$ & $0.014 \pm 0.0003$ & $14.1 \pm 1.6$ & $842 \pm 45$ \\
\hline$+20 \mathrm{wt} \% \mathrm{Cu}-\mathrm{CNF}$ & $0.009 \pm 0.003$ & $13.2 \pm 2.4$ & $835 \pm 22$ \\
\hline$+30 \mathrm{wt} \% \mathrm{Cu}-\mathrm{CNF}$ & $0.007 \pm 0.003$ & $11.0 \pm 3.4$ & $15.5 \pm 1$ \\
\hline$+20 \mathrm{wt} \% \mathrm{Ni}-\mathrm{CNF}$ & $0.007 \pm 0.002$ & $10.2 \pm 2.6$ & $748 \pm 59$ \\
\hline$+30 \mathrm{wt} \% \mathrm{Ni}-\mathrm{CNF}$ & $0.013 \pm 0.001$ & $9.2 \pm 0.8$ & $538 \pm 41$ \\
\hline$+20 \mathrm{wt} \% \mathrm{Ni}-\mathrm{nanostrands}$ & $0.012 \pm 0.003$ & $16.2 \pm 1.0$ & $872 \pm 32$ \\
\hline$+30 \mathrm{wt} \% \mathrm{Ni}-\mathrm{nanostrands}$ & $0.012 \pm 0.003$ & $5.8 \pm 1.7$ & $531 \pm 77$ \\
\hline$+20 \mathrm{wt} \% \mathrm{BN}$ & $0.023 \pm 0.003$ & $16.7 \pm 3.0$ & $714 \pm 52$ \\
\hline$+30 \mathrm{wt} \% \mathrm{Al}+20 \mathrm{wt} \% \mathrm{MWCNT}$ & $0.140 \pm 0.01$ & $11.4 \pm 1.3$ & $49 \pm 7$ \\
\hline$+30 \mathrm{wt} \% \mathrm{Al}+30 \mathrm{wt} \% \mathrm{MWCNT}$ & $*$ & $*$ & $*$ \\
\hline$+30 \mathrm{wt} \% \mathrm{Al}+20 \mathrm{wt} \% \mathrm{mod} \mathrm{MWCNT}$ & & & \\
$(\mathrm{electrostatic})$ & $0.087 \pm 0.008$ & $8.9 \pm 1.0$ & $90 \pm 18$ \\
\hline$+30 \mathrm{wt} \% \mathrm{Al}+20 \mathrm{wt} \% \mathrm{CNF}$ & $0.065 \pm 0.004$ & $6.6 \pm 2.2$ & $149 \pm 66$ \\
\hline$+30 \mathrm{wt} \% \mathrm{Al}+30 \mathrm{wt} \% \mathrm{CNF}$ & $*$ & $*$ & $*$ \\
\hline$+30 \mathrm{wt} \% \mathrm{Al}+20 \mathrm{wt} \% \mathrm{EG}$ & $0.106 \pm 0.011$ & $8.3 \pm 0.8$ & $95 \pm 30$ \\
\hline$+30 \mathrm{wt} \% \mathrm{Al}+30 \mathrm{wt} \% \mathrm{EG}$ & $0.179 \pm 0.035$ & $11.7 \pm 0.5$ & $61 \pm 10$ \\
\hline
\end{tabular}


Table 3: TC of Elvax ${ }^{\text {TM }}$ 260/nanofiller samples:

\begin{tabular}{|c|c|c|c|}
\hline Sample & $\begin{array}{c}\text { Thermal } \\
\text { Conductivity } \\
\text { (perpendicular), } \\
\text { W/mK }\end{array}$ & $\begin{array}{c}\text { Thermal } \\
\text { Conductivity } \\
\text { (parallel), } \\
\text { W/mK }\end{array}$ & $\begin{array}{c}\text { Thermal } \\
\text { Conductivity } \\
\text { (tubes), } \\
\text { W/mK }\end{array}$ \\
\hline Neat Elvax $260^{\mathrm{TM}}$ & 0.311 & 0.324 & 0.26 \\
\hline$+20 \mathrm{wt} \% \mathrm{MWCNT}$ & 0.356 & 2.318 & 2.93 \\
\hline $\begin{array}{l}+20 \mathrm{wt} \% \text { mod MWCNT } \\
\text { (electrostatic attachment); } \\
\text { covalent attachment }\end{array}$ & $\begin{array}{c}0.573 \\
--\end{array}$ & $\begin{array}{c}3.395 \\
--\end{array}$ & 3.36 \\
\hline$+30 \mathrm{wt} \% \mathrm{MWCNT}$ & 0.469 & 2.942 & 4.40 \\
\hline$+20 \mathrm{wt} \% \mathrm{CNF}$ & 0.409 & 1.949 & 3.02 \\
\hline$+30 \mathrm{wt} \% \mathrm{CNF}$ & 0.486 & 2.872 & 3.51 \\
\hline$+20 \mathrm{wt} \% \mathrm{EG}$ & 0.399 & 3.000 & 3.80 \\
\hline$+20 \mathrm{wt} \% \bmod \mathrm{EG}$ (covalent) & -- & -- & 2.27 \\
\hline$+30 \mathrm{wt} \% \mathrm{EG}$ & 0.509 & 4.359 & 4.04 \\
\hline$+30 \mathrm{wt} \%$ mod EG (covalent) & -- & -- & 3.38 \\
\hline$+40 \mathrm{wt} \% \mathrm{EG}$ & 0.544 & 5.554 & 5.49 \\
\hline$+40 \mathrm{wt} \% \bmod \mathrm{EG}$ (electrostatic) & 0.444 & 4.562 & 5.54 \\
\hline$+20 \mathrm{wt} \% \mathrm{Ag}-\mathrm{CNF}$ & 0.346 & 0.488 & -- \\
\hline$+30 \mathrm{wt} \% \mathrm{Ag}-\mathrm{CNF}$ & -- & 0.484 & -- \\
\hline$+20 \mathrm{wt} \% \mathrm{Cu}-\mathrm{CNF}$ & -- & 0.447 & -- \\
\hline$+30 \mathrm{wt} \% \mathrm{Cu}-\mathrm{CNF}$ & -- & 0.540 & -- \\
\hline$+20 \mathrm{wt} \% \mathrm{Ni}-\mathrm{CNF}$ & -- & 0.523 & -- \\
\hline$+30 \mathrm{wt} \% \mathrm{Ni}-\mathrm{CNF}$ & -- & 0.660 & -- \\
\hline$+20 \mathrm{wt} \%$ Ni-nanostrands & -- & 0.526 & -- \\
\hline$+30 \mathrm{wt} \%$ Ni-nanostrands & -- & 0.550 & -- \\
\hline$+20 \mathrm{wt} \% \mathrm{BN}$ & 0.311 & 0.866 & -- \\
\hline$+30 \mathrm{wt} \% \mathrm{Al}+20 \mathrm{wt} \% \mathrm{MWCNT}$ & 0.725 & 3.299 & 3.45 \\
\hline$+30 \mathrm{wt} \% \mathrm{Al}+30 \mathrm{wt} \% \mathrm{MWCNT}$ & 1.025 & 3.853 & 4.82 \\
\hline $\begin{array}{l}+30 \mathrm{wt} \% \text { Al }+20 \text { wt } \% \text { mod } \\
\text { MWCNT (electrostatic attachment) }\end{array}$ & 0.691 & 2.551 & 2.75 \\
\hline$+30 \mathrm{wt} \% \mathrm{Al}+20 \mathrm{wt} \% \mathrm{CNF}$ & 0.734 & 2.533 & 2.78 \\
\hline$+30 \mathrm{wt} \% \mathrm{Al}+30 \mathrm{wt} \% \mathrm{CNF}$ & 0.983 & 3.645 & 4.80 \\
\hline$+30 \mathrm{wt} \% \mathrm{Al}+20 \mathrm{wt} \% \mathrm{EG}$ & 0.857 & 3.337 & 2.73 \\
\hline$+30 \mathrm{wt} \% \mathrm{Al}+30 \mathrm{wt} \% \mathrm{EG}$ & -- & -- & 6.24 \\
\hline
\end{tabular}


Table 4: TC of Elvax ${ }^{\text {TM }}$ 260/nanofiller LMM samples (unoriented):

\begin{tabular}{|l|c|}
\hline Sample & Thermal Conductivity, W/mK \\
\hline Neat Elvax ${ }^{\mathrm{TM}} 260$ & 0.324 \\
\hline$+20 \mathrm{wt} \% \mathrm{MWCNT}$ & 0.555 \\
\hline$+20 \mathrm{wt} \%$ mod MWCNT (electrostatic) & 0.655 \\
\hline$+30 \mathrm{wt} \% \mathrm{MWCNT}$ & 0.705 \\
\hline$+20 \mathrm{wt} \% \mathrm{CNF}$ & 0.634 \\
\hline$+30 \mathrm{wt} \% \mathrm{CNF}$ & 0.643 \\
\hline$+20 \mathrm{wt} \% \mathrm{EG}$ & 0.666 \\
\hline$+30 \mathrm{wt} \% \mathrm{EG}$ & 0.902 \\
\hline$+40 \mathrm{wt} \% \mathrm{EG}$ & 1.369 \\
\hline$+40 \mathrm{wt} \%$ mod EG (electrostatic) & 1.030 \\
\hline$+50 \mathrm{wt} \%$ mod EG (covalent) & 2.460 \\
\hline
\end{tabular}

Table 5a: Radius of Curvature of Elvax ${ }^{\mathrm{TM}} 260 / 30$ wt \% Al/nanofiller tubing:

\begin{tabular}{|l|c|c|c|c|c|c|c|}
\hline $\begin{array}{l}\text { Diameter, } \\
\mathrm{cm}\end{array}$ & $\begin{array}{l}20 \mathrm{wt} \% \\
\text { MWCNT }\end{array}$ & $\begin{array}{l}30 \mathrm{wt} \% \\
\text { MWCNT }\end{array}$ & $\begin{array}{l}20 \mathrm{wt} \% \\
\mathrm{CNF}\end{array}$ & $\begin{array}{l}30 \mathrm{wt} \% \\
\mathrm{CNF}\end{array}$ & $\begin{array}{l}20 \mathrm{wt} \% \\
\mathrm{EG}\end{array}$ & $\begin{array}{l}30 \mathrm{wt} \% \\
\text { EG }\end{array}$ & $\begin{array}{l}20 \mathrm{wt} \\
\text { mod } \\
\text { MWCNT }\end{array}$ \\
\hline 4.18 & $\sqrt{ }$ & $\sqrt{ }$ & $\sqrt{ }$ & $\sqrt{ }$ & $\sqrt{ }$ & $\sqrt{ }$ & $\sqrt{ }$ \\
\hline 3.77 & $\sqrt{ }$ & $\sqrt{ }$ & $\sqrt{ }$ & $\sqrt{ }$ & $\sqrt{ }$ & $\sqrt{ }$ & $\sqrt{ }$ \\
\hline 3.58 & $\sqrt{ }$ & $\sqrt{ }$ & $\sqrt{ }$ & $\sqrt{ }$ & $\sqrt{ }$ & $\sqrt{ }$ & $\sqrt{ }$ \\
\hline 3.27 & $\sqrt{ }$ & $\sqrt{ }$ & $\sqrt{ }$ & $\sqrt{ }$ & $\sqrt{ }$ & $\sqrt{ }$ & $\sqrt{ }$ \\
\hline 3.21 & $\sqrt{ }$ & $\sqrt{ }$ & $\sqrt{ }$ & $\sqrt{ }$ & $\sqrt{ }$ & $\sqrt{ }$ & $\sqrt{ }$ \\
\hline 2.98 & $\sqrt{ }$ & $\sqrt{ }$ & $\sqrt{ }$ & $\sqrt{ }$ & $\sqrt{ }$ & $\sqrt{ }$ & $\sqrt{ }$ \\
\hline 2.85 & $\sqrt{ }$ & $\sqrt{ }$ & $\sqrt{ }$ & $\sqrt{ }$ & $\sqrt{ }$ & $\sqrt{ }$ & $\sqrt{ }$ \\
\hline 2.56 & $\sqrt{ }$ & $\sqrt{ }$ & $\sqrt{ }$ & $\sqrt{ }$ & $\sqrt{ }$ & $\sqrt{ }$ & $\sqrt{ }$ \\
\hline 2.42 & $\sqrt{ }$ & $\sqrt{ }$ & $\sqrt{ }$ & $\sqrt{ }$ & $\sqrt{ }$ & $\mathbf{x}$ & $\sqrt{ }$ \\
\hline
\end{tabular}

$\sqrt{ }$ - no kinking; $\mathrm{x}$ - kinking 
Table 5b: Radius of Curvature of Elvax ${ }^{\mathrm{TM}}$ 260/nanofiller tubing:

\begin{tabular}{|c|c|c|c|c|c|c|c|c|c|c|}
\hline $\begin{array}{l}\text { Diameter, } \\
\mathrm{cm}\end{array}$ & $\begin{array}{l}20 \mathrm{wt} \% \\
\mathrm{MWCNT}\end{array}$ & $\begin{array}{l}30 \mathrm{wt} \% \\
\text { MWCNT }\end{array}$ & $\begin{array}{l}20 \\
w t \% \\
\text { CNF }\end{array}$ & $\begin{array}{l}30 \\
\mathrm{wt} \% \\
\mathrm{CNF}\end{array}$ & $\begin{array}{l}40 \\
w t \% \\
\text { CNF }\end{array}$ & $\begin{array}{l}20 \\
w t \% \\
E G\end{array}$ & $\begin{array}{l}30 \\
w t \% \\
\text { EG }\end{array}$ & $\begin{array}{l}40 \\
w t \% \\
E G\end{array}$ & $\begin{array}{l}40 \\
w t \% \\
\bmod \\
\text { EG }\end{array}$ & $\begin{array}{l}20 \quad \mathrm{wt}^{\circ} \% \\
\bmod \\
\mathrm{MWCNT}\end{array}$ \\
\hline 4.18 & $\sqrt{ }$ & $\sqrt{ }$ & $\sqrt{ }$ & $\sqrt{ }$ & $\mathrm{x}$ & $\sqrt{ }$ & $\sqrt{ }$ & $\mathrm{x}$ & $\sqrt{ }$ & $\sqrt{ }$ \\
\hline 3.77 & $\sqrt{ }$ & $\sqrt{ }$ & $\sqrt{ }$ & $\sqrt{ }$ & $\mathrm{X}$ & $\sqrt{ }$ & $\sqrt{ }$ & $\mathrm{X}$ & $\sqrt{ }$ & $\sqrt{ }$ \\
\hline 3.58 & $\sqrt{ }$ & $\sqrt{ }$ & $\sqrt{ }$ & $\sqrt{ }$ & $\mathrm{x}$ & $\sqrt{ }$ & $\sqrt{ }$ & $\mathrm{x}$ & $\sqrt{ }$ & $\sqrt{ }$ \\
\hline 3.27 & $\sqrt{ }$ & $\sqrt{ }$ & $\sqrt{ }$ & $\sqrt{ }$ & $x$ & $\sqrt{ }$ & $\sqrt{ }$ & $\mathrm{x}$ & $\sqrt{ }$ & $\sqrt{ }$ \\
\hline 3.21 & $\sqrt{ }$ & $\sqrt{ }$ & $\sqrt{ }$ & $\sqrt{ }$ & $\mathrm{X}$ & $\sqrt{ }$ & $\mathrm{X}$ & $\mathrm{X}$ & $\sqrt{ }$ & $\sqrt{ }$ \\
\hline 2.98 & $\sqrt{ }$ & $\mathrm{X}$ & $\sqrt{ }$ & $\sqrt{ }$ & $\mathrm{X}$ & $\mathrm{X}$ & $\mathrm{X}$ & $\mathrm{X}$ & $\mathrm{x}$ & $\sqrt{ }$ \\
\hline 2.85 & $\sqrt{ }$ & $\mathrm{X}$ & $\sqrt{ }$ & $\sqrt{ }$ & $\mathrm{X}$ & $\mathrm{X}$ & $\mathrm{x}$ & $\mathrm{X}$ & $x$ & $\sqrt{ }$ \\
\hline 2.56 & $\mathrm{X}$ & $\mathrm{X}$ & $\sqrt{ }$ & $\sqrt{ }$ & $\mathrm{X}$ & $\mathrm{X}$ & $\mathrm{X}$ & $\mathrm{X}$ & $\mathrm{X}$ & $\sqrt{ }$ \\
\hline 2.42 & $x$ & $\mathrm{X}$ & $\sqrt{ }$ & $\sqrt{ }$ & $\mathrm{x}$ & $\mathrm{X}$ & $\mathrm{X}$ & $\mathrm{X}$ & $\mathrm{x}$ & $\sqrt{ }$ \\
\hline
\end{tabular}

$\sqrt{ }$ - no kinking ; $\mathrm{x}$ - kinking 


\section{REFERENCES}

1. Lozano K, Yang S and Zeng Q, J. Appl. Poly. Sci. 2004; 93(1): 155-162.

2. Kuriger RJ, Alam MK, Anderson DP and Jacobsen RL, Composites, Part A 2002; 33: 53-62.

3. Lozano K, Bonilla-Rios J and Barrera EV, J. Appl. Poly. Sci. 2001; 79(1): 125-133.

4. Carneiro OS, Covas JA, Bernardo CA, Caldeira G, Van Hattum FWJ, Ting JM, Alig RL and Lake ML; Composites Sci. Tech. 1998; 58: 401-07.

5. Pogue RT, Ye J, Klosterman DA, Glass AS and Chartoff RP, Composites: Part A 1998, 29: $1273-81$.

6. Cooper CA, Ravich D, Lips D, Mayer J and Wagner HD, Composites Sci. Tech. 2002; 62: $1105-12$.

7. Gao X, Liu L, Guo Q, Shi J and Zhai G, Materials Letters 2005; 59: 3062-65.

8. Lau KT and Hui D, Composites Part B: Engineering 2002; 33: 263-77.

9. Liu CH, Huang H, Wu Y and Fan SS, Appl. Phys. Lett. 2004; 84(21): 4248-50.

10. Kim P, Shi L, Majumdar A and McEuen PL, Phys. Rev. Lett. 2001; 87(21): 215502-1-4.

11. Drzal LT and Fukushima H, Unites States Patent Application Publication, Pub No. US20040127621 (2004).

12. Shen JW, Huang WY, Zuo SW and Hou J, J. Appl. Polym. Sci. 2005; 97(1): 51-59.

13. Zheng W, Lu X and Wong SC, J. Appl. Polym. Sci. 2004; 91(5): 2781-88.

14. Zheng G, Wu J, Wang W and Pan C, Carbon 2004; 42: 2839-47.

15. Zheng W, Wong SC and Sue HJ, Polymer 2002; 43: 6767-73.

16. Song LN, Xiao M, Li XH and Meng YZ, Mater. Chem. Phys. 2005, 93, 122-28.

17. Cho D, Lee S, Yang G, Fukushima H and Drzal LT, Macromol. Mater. Eng. 2005; 290(3): 179-87. 
18. http://materialsri.com/

19. Gibson, T., Rice, B., Ragland, W., Silverman, E.M., Peng, H., Strong, K.L. and Moon, D., SAMPE Technical Conference Proceedings, Long Beach, CA, May 1-5, 2005.

20. Burghardt J, Hansen N, Hansen L, Hansen G, SAMPE Technical Conference Proceedings, Long Beach, CA, April 30 - May 4, 2006

21. Hansen G, Proceedings of SAMPE 2006, Long Beach, CA, April 30 - May 4, 2006

22. Dong, H., Fan, L. and Wong, C.P. Proceedings of 2005 Electronic Components and Technology Conference.

23. Ruh1, R., Donaldson, K.Y. and Hasselman, D.P.H., J. Am. Cer. Soc. 1992; 75(10): 2887-90.

24. Duclaux, L., Nysten, B., Issi, J-P., and Moore, A. W., Physical Review B 1992; 46: 3362-7.

25. Park C, Ounaies Z, Watson KA, Crooks RE, Smith Jr. JG, Lowther SE, Connell JW, Siochi EJ, Harrison JS and St. Clair TL, Chem. Phys. Lett. 2002; 364: 303-08.

26. Smith Jr. JG, Connell JW, Delozier DM, Lillehei PT, Watson KA, Lin Y, Zhou B and Sun YP, Polymer 2004, 45: 825-836.

27. Haggenmueller R, Gommans HH, Rinzler AG, Fischer JE and Winey KI, Chem. Phys. Lett. 2000; 330: 219-25.

28. Andrews R, Jacques D, Minot M and Rantell T, Macromol. Mater. Eng. 2002; 287(6): 395403.

29. Banerjee S, Hemraj-Benny T and Wong SS, Adv. Mater. 2005; 17(1): 17-29.

30. Hwang YJ, Ahn YC, Shin HS, Lee CG, Kim GT, Park HS and Lee JK, Current Appl. Phys. 2006; 6(6): 1068-71. 
31. Choi SUS, Zhang ZG, Yu W, Lockwood FE and Grulke EA, Appl. Phys. Lett. 2001; 79(14): 2252-54.

32. Osman MA and Srivastava D, Nanotechnology 2001; 12: 21-24.

33. Gong Q, Li Z, Bai X, Li D, Zhao Y and Liang J, Mater. Sci. Eng. A 2004; 384: 209-14.

34. Ghose S, Watson KA, Working DC, Criss JM, Siochi EJ and Connell JW, High Performance Polymers 2006, 18 (4), 527-544.

35. Ghose S, Watson KA, Sun KJ, Criss JM, Siochi EJ and Connell JW, Composite Science and Technology 2006, 66, 1995-2002.

36. Shenogin S, Xue L, Ozisik R and Keblinski P, J. Appl. Phys. 2004; 95(12): 8136-44.

37. Shenogin S, Bodapati A, Xue L, Ozisik R and Keblinski P, Appl. Phys. Lett. 2004; 85(12): 2229-31.

38. Clancy TC and Gates TS, Polymer 2006; 47: 5990-5996.

39. Ghose S, Watson KA, Delozier DM, Working DC, Connell JW, Smith Jr JG, Sun YP and Lin Y, High Performance Polymers 2006; 18 (6): 961-977.

40. Crist, B., Annu. Rev. Mater. Sci. 1995, 25: 295-323.

41. Jadhav A, Woldesenbet E, Pang S, Composites: Part B 2003; 34: 339-346.

42. Huang H, Liu C, Wu Y and Fan S, Adv. Mater. (Communications) 2005; 17: 1652-56.

43. Huxtable ST, Cahill DG, Shenogin S, Xue L, Ozisik R, Barone P, Usrey M, Strano MS, Siddons G, Shim M and Keblinski P, Nat. Mater. 2003; 2(11): 731-34.

44. Chen YM and Ting JM, Carbon 2002; 40: 359-62.

45. Ye CM, Shentu BQ, Weng ZX, Cover Image, J. Appl. Poly. Sc., 2006; 101(6): 3806-3810 
46. Weaver G, and Bue G; "Analysis Report for the Lightweight Liquid Cooling and Ventilation Garment Study”, LMSEAT 34171, Contract NAS 9-19100, June 2003. 